A N N A L E S Annales de Bretagne et des Pays de l'Ouest

\title{
In memoriam Bernard Merdrignac (1947-2013)
}

\section{Daniel Pichot}

\section{OpenEdition}

\section{Journals}

Édition électronique

URL : http://journals.openedition.org/abpo/2665

DOI : $10.4000 / a b p o .2665$

ISBN : 978-2-7535-3304-2

ISSN : 2108-6443

Éditeur

Presses universitaires de Rennes

Édition imprimée

Date de publication : 30 décembre 2013

Pagination : 7-8

ISBN : 978-2-7535-3302-8

ISSN : 0399-0826

Référence électronique

Daniel Pichot, «In memoriam Bernard Merdrignac (1947-2013) ». Annales de Bretagne et des Pays de

I'Ouest [En ligne], 120-4 | 2013, mis en ligne le 30 décembre 2013, consulté le 23 septembre 2020

URL : http://journals.openedition.org/abpo/2665 ; DOI : https://doi.org/10.4000/abpo.2665 


\title{
In memoriam
}

\section{Bernard Merdrignac (1947-2013)}

\author{
Texte lu par Daniel Pichot lors de la sépulture de B. Merdrignac \\ dans la vieille église de Saint-Lunaire, le 15 octobre 2013.
}

Bernard,

Tu n'as pas souhaité d'hommage officiel ou institutionnel mais tu as voulu qu'aujourd'hui les proches, les amis, se retrouvent autour de toi pour un dernier adieu dans cette vieille église de saint Lunaire, clin d'œil à ce qui fut le travail de toute une vie, les saints de Bretagne. Respectueux de ta volonté, ces quelques mots seront d'amitié avant tout mais il n'est guère possible de ne pas te remercier pour ce que tu nous as apporté. Il me faut dire ce que tu lègues après une vie bien remplie tant sur le plan professionnel, l'histoire, ta passion plus qu'un métier, mais aussi sur un plan beaucoup plus personnel.

Historien tu fus avant tout. Arrivé à la Faculté des Lettres de Rennes dans les années 60 , tu entames des études d'histoire et, rapidement séduit par l'enseignement d'André Chédeville qui demeura toujours pour toi comme pour d'autres, une référence, le Moyen Âge t'attire irrémédiablement. Cela te conduit à une thèse de $3^{\text {e }}$ cycle sur un sujet un peu étonnant, l'hagiographie bretonne. Relisant les vies des saints à la lumière du structuralisme et des recherches les plus récentes sur le récit, tu rénoves fondamentalement cette discipline, la réinsérant dans le champ de l'histoire religieuse et culturelle. Par la suite, les saints des premiers temps bretons sont demeurés ta fréquentation la plus assidue, saint Guénolé, saint Samson étaient devenus tes compagnons quotidiens.

Cela te permet de pénétrer à l'Université : maître de conférences puis professeur. Les saints assurèrent la base de ton enseignement et des nombreuses recherches que tu dirigeas. Tu t'imposes alors, Bernard, comme l'un des historiens majeurs des siècles du haut Moyen Âge breton et, en compagnie de Pierre-Roland Giot l'anthropologue et de Philippe Guigon l'archéologue, tu proposes une histoire des « Premiers bretons d'Armorique ". Logiquement, tu participes à bien des aventures intellectuelles dont le CIRDoMoC que tu as longtemps animé à l'abbaye de Landevennec, et tu présides pendant de longues années l'association des Annales de Bretagne et des Pays de l'Ouest, sans parler de ta direction du laboratoire Pierre Merlat.

Tes publications se multiplient et, surtout, tu sais entretenir de nombreuses relations avec des chercheurs en France et à l'étranger, au Pays de Galles, en Irlande. Chercheur passionné, tu fais preuve d'une érudition majeure, souvent éblouissante, connaissant dans les moindres détails tes vies de saints, repérant sans problème une citation biblique. Tu sais organiser cela en de puissants et subtils raisonnements, ne craignant pas la discussion, voire la polémique intellectuelle que tu adores. Pour toi, le débat est au cœur de la recherche. 


\section{In memoriam}

Tes curiosités t'entraînent souvent ailleurs et même, non sans paradoxe, à écrire un ouvrage qui fait autorité sur le Sport au Moyen Âge. J'évoquerai plus particulièrement le dernier livre que nous avons dirigé ensemble La Paroisse, communauté et territoire. Deux années de réunions, de débats, de communications réunissant des gens fort divers mais qui apportaient au travail commun. Tu as pu voir le livre sortir, il est le fruit d'une coopération passionnante, passionnée et amicale de ceux que tu appelais les "paroissiens".

Ce type de travail que tu aimais résume assez bien l'homme, le collègue, l'ami. Homme de cabinet, tu étais incontestablement, mais professeur aussi. Après une longue expérience acquise dans l'enseignement technique, de Rostrenen à SaintMalo en passant par Saint-Nazaire où tu apprends la pratique d'un métier exigeant, tu t'adaptes sans problèmes aux amphithéâtres de l'université. Tu y dispenses des cours qui savent capter l'intérêt et tu séduis suffisamment d'étudiants pour qu'ils souhaitent fréquenter le séminaire de maîtrise puis de master et s'engager dans des études souvent austères mais que la chaleur de ta direction, ta bonhommie, ton engagement personnel, savent rendre attrayantes. Tout cela donne naissance à des thèses que tu laisses s'épanouir éventuellement assez loin de tes préoccupations, tu es un directeur exigeant mais qui laisse la liberté.

Tu fus un collègue bien présent autant dans les couloirs que dans les instances de l'université dont tu connaissais les rouages et tu as animé nos réunions de tes réparties et autres facéties dont tu étais coutumier. L'humour taquin comme tu le précisais s'exerçait à tout moment et envers tous, y compris toi-même. C'était ta façon de rompre avec les traditions universitaires trop paralysantes, tout comme ta silhouette peu classique, casquette et canne noueuse, proposait un personnage quelque peu décalé qui comptait dans le paysage du département. Dernier avatar de cette tendance bien affirmée, tu t'es tourné vers le roman policier, médiéval bien sûr, et quelque peu inattendu.

Tu cultivais les amitiés et tu as gardé des liens avec le groupe formé dès les années universitaires. Tu en as conservé le surnom de Francis qui aujourd'hui demeure pour quelques-uns. Ton amitié choisie était réelle et totale, elle s'exprimait aussi bien dans les réunions et les fêtes que par une assistance désintéressée, capable d'éclairer la traduction d'une charte coriace, de rechercher une référence.

Il me faudrait encore dire tes passions, tes goûts. Tu aimais retourner en Irlande, tu y retrouvais les traces d'un peuple de saints et ton dernier voyage fut encore, ce printemps, pour l'île de saint Patrick. Enfin, ces dernières années, tu as affiché un courage masqué par un humour toujours présent. Tu ne te fis guère d'illusion et tu as affronté avec aplomb, sans faiblir, la maladie, sans jamais accepter de capituler.

Quelques mots pour retracer une vie, évoquer un homme tel que toi c'est peu. Tu as trop donné pour que l'on t'oublie. Puisses-tu désormais trouver la paix et que tes amis que tu as si bien servi, la cohorte des saints bretons, saint Conwoïon, saint Samson, saint Guénolé, saint Lunaire, bien sûr, te soient secourables...

Merci Bernard 